\title{
Boons amidst the banes- during COVID-19 pandemic
}

Neethu George ${ }^{1}$, Rock Britto ${ }^{2}$, Nawin Jai Vignesh ${ }^{3}$, Janani Shree Suresh ${ }^{4}$, Jaswini Navarajan ${ }^{5}$, Jayashree Shanmugam ${ }^{6}$

${ }^{1}$ Assistant Professor, Department of Community Medicine, Dhanalakshmi Srinivasan Medical College Hospital, Perambalur, Tamilnadu; ${ }^{2}$ Associate Professor, Department of Community Medicine, Dhanalakshmi Srinivasan Medical College Hospital, Perambalur, Tamilnadu; ${ }^{3}$ Post Graduate student, Department of Community Medicine, Dhanalakshmi Srinivasan Medical College Hospital, Perambalur, Tamilnadu; ${ }^{4}$ Intern, Department of Community Medicine, Dhanalakshmi Srinivasan Medical College Hospital, Perambalur, Tamilnadu; ${ }^{5}$ Intern, Department of Community Medicine, Dhanalakshmi Srinivasan Medical College Hospital, Perambalur, Tamilnadu; ${ }^{6}$ Intern, Department of Community Medicine, Dhanalakshmi Srinivasan Medical College Hospital, Perambalur, Tamilnadu

\begin{tabular}{|c|c|c|c|c|c|c|c|c|}
\hline Abstract & Introduction & Methodology & Results & Conclusion & References & Citation & \multicolumn{2}{|c|}{ Tables / Figures } \\
\hline \multicolumn{9}{|c|}{ orresponding Author } \\
\hline \multicolumn{8}{|c|}{$\begin{array}{l}\text { Dr. Neethu George, Assistant Professor, Department of Community Medicine, Dhanalakshmi Srinivasan } \\
\text { Medical College, Perambalur Tamil Nadu, India. } \\
\text { E Mail ID: neethumampuzha@gmail.com }\end{array}$} & 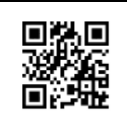 \\
\hline
\end{tabular}

\section{Citation}

George N, Britto R, Vignesh NJ, Suresh JS, Navarajan J, Shanmugam J. Boons amidst the banes- during COVID 19 pandemic. Indian J Comm Health. 2021;33(3):528-530. https://doi.org/10.47203/IJCH.2021.v33i03.022

Source of Funding: Nil Conflict of Interest: None declared

\section{Article Cycle}

Received: 29/05/2021; Revision: 20/07/2021; Accepted: 28/08/2021; Published: 30/09/2021

This work is licensed under a Creative Commons Attribution 4.0 International License.

\section{Abstract}

India recorded its first Covid-19 positive case in Kerala on January 30, 2020. This was followed by nationwide lockdown in 4 different phases from 25th March to 31st May 2020 and an unlock period thereafter. This pandemic brought many unseen challenges to the world. On one side human lives were put at risk, on the other side nature was recreating itself. Many diseases other than covid dropped down in massive percentage. The public understood the importance of handwashing, vaccination, covering mouth and nose while coughing and sneezing during this pandemic. Children facing this Covid pandemic had understood the importance of the role played by hygiene and social distancing in maintaining a healthy lifestyle. Every coin has two faces, likewise, this pandemic has both positive and negative effects and we focus on positive effects in this article.

\section{Keywords}

Boons; Banes; COVID-19; Pandemic; Mouth; Hygiene

\section{Introduction}

"It is not the strongest or the most intelligent who will survive but those who can best manage change."

By Charles Darwin

Since the dawn of scientific era, medicine and science has seen various new inventions and has been under rapid development. Despite the developments in field of medicine, COVID-19 has successfully emerged as devastating disease and as a global health problem. The COVID-19 pandemic is continuing its deadly path and causing a serious physiological and psychological trauma to many even at present. The burden it caused in economy and health of a country is huge, but it also brought some good changes among human behaviour and in environment. There is an old saying, "With Bad, always comes the Good". As the saying goes, there has occurred some good changes like reduced incidence of other diseases, good changes in psychological health, environmental health and in human behaviour. The current article is aimed to discuss those the positive changes that has occurred because of COVID-19.

Pandemic had made multiple changes in all walks of population and few positive effects among each population is given down. (Figure 1) shows the general positive and negative effects

- Children: Even though schools are closed these group got exposed to a new type of parenting with more stress on spending quality time, enjoying the time of sunrise and set and to the impact of getting acquainted with local materials. The acts of learning new skills in education or outdoors made to increase the selfconfidence and also the development of spending time 
in groups made the group more exposed to new found values.(1)The importance of being clean and hygienic got emphasized and also to be content with the present situation

- Adults: The absence of stressed mornings and workplace, presence of comfort at home and change in the attitude of parenting makes these group more vibrant during the pandemic. The return of many, towards the dusted habits and the change in dietary as well as sleep behaviours would have made a positive impact in their health. The time have made everyone to be in good, closed relationship with near ones and feeling change of mine to ours happened.

- Elderly- the presence of more amount of people around this group made them come out of loneliness and the change of back to nature would have been an added advantage.

The positive effects can be detailed under various heading below.

\section{Environmental effect}

Humanity retreats indoors and the non-human natural world rumbles out liberated. Notoriously dirty, the waterways and rivers in the world look cleaner, the air fresher, the smog gone, the haze dispersed, and the wildlife has filled the open spaces, coronavirus lockdowns across the world seem to have several positive effects on the environment. Millions of people have been cooped up indoors, but the natural world outside has continued to rumble on, and the natural world is benefiting from our absence. Here are some positive effects on the environment.

Never has occurred such irony in life. The air is pure but wearing masks is mandatory. The most abundant air pollutants in cities and industrial areas are Nitrogen dioxide (NO2), Sulphur dioxide (SO2), Particulate matter (PM10). These air pollutants, which are responsible for various cardiovascular and respiratory diseases have found to significantly decreased during the Covid-19 Lockdown. The primary sources of these pollutants are vehicular exhaust, road dust, and from mainly metal processing industries. Most of the health benefits were observed with the reduction in NO2. Continuous improvement has occurred in Air Quality Index (AQI) in some of the Indian metropolitan cities during the lockdown. According to present situation, the AQI is better even than the standards set by WHO and Central Pollution Control Board (CPCB). As the air quality improved, incidence of many respiratory and cardiovascular diseases has also decreased. $(2,3)$

The quality of drinking water and the water bodies is also improving amidst the covid-19 lockdown. The temporary shutdown of industries and their discharge of effluent wastes into the water led to apparent positive effects on water quality. According to the concerned organisation reports, many rivers and water bodies quality in India are improved in the past year. Clean rivers and other water bodies have made a significant positive effect on aquatic life. More marine animals are returning to their actual habitats. Since beaches are people free, indigestion and entanglement due to plastic and marine debris which are the leading cause of injuries to sea creatures have been wiped out during these lockdowns. $(2,4)$

\section{Health and Covid-19}

A decrease in air pollutants resulted in a decrease in respiratory and cardiovascular diseases. PM2.5 a major air pollutant and a carcinogen has been decreased significantly during this lockdown. Active lifestyle modifications such as regular exercise and yoga have turned people life more towards a healthy future. Awareness towards vaccination, hand hygiene, social distancing has been increased. Awareness of diet and food habits has a promising positive effect on noncommunicable disease like diabetes mellitus and hypertension. (2,5) Many hospitals were reporting a smaller number of cases - even though it is a positive effect, yet another hypothetical reason can be under reporting, lack of access, non-botheration, fear of contact of Covid-19

Since many people were confined within home during the lockdown, family ties and relationships improved. Crime incidents like Robbery and Automobile theft has reduced and has improved the overall mental and social health of community. Loneliness has decreased which has been a major cause of depression. People's view on life has become broader. Many extracurricular activities have become a part of daily life. Gardening has been increasingly showing a promising best future. People learnt skills needed for survival. The Covid-19 has given a new sense of appreciation and gratefulness. This has also made us mentally strong. $(2,6)$

\section{Generalised sector effect}

Many corporate sectors have joined in hands with NonGovernmental Organisations (NGO) to help front line workers during this pandemic showing a great sign of humanity. (2) During this lockdown almost every class, office meetings were online which resulted in the generation of new apps. This promises the best effective virtual learning possibilities in the upcoming future. (2) The overall rate of road traffic accidents has been decreased during this lockdown. Less movement during this lockdown resulted in less trauma. (7)

\section{Studies conducted about the topic}

- Studies conducted showed death due to air pollution was around 67000 deaths/year before lockdown which dropped to almost $50 \%$ after lockdown. There was also a $50 \%$ reduction in hospital admission for respiratory diseases as the primary air pollutants responsible for respiratory illnesses like PM10 reduced due to lockdown. (8)

- Covid-19 has minimised the movement of humans, showing changes like never seen before. Many studies were conducted to see the effect of COVID 19 and RTA. 
In this following study all the trauma patients coming to Rural Hospital, Wardha were included regardless of their age and mode of trauma. The period of two weeks before and two weeks after the initiation of lockdown in India were studied. They have noted a significant fall in overall trauma cases as anticipated due to the lockdown. There was a fall in the total number of cases by around three times. (7)

- The oil prices dropped, $17 \%$ less petrol and $25 \%$ less diesel in March 2020, as compared to March 2019.This comes after the beginning of a country-wide lockdown, where all major transportation has been stopped to control and contain the spread of the novel coronavirus. The falling rates of crude oil would leave more liquid cash in the hands of the vehicle owners by the end of 2020. (9)

- Crime rates in Delhi and Gurugram have fallen in the last month after the COVID-19 fear almost paralyzed the cities. The drop in crime rates parallels to the reduction in the percentage of vehicle thefts, which has given some mental peace to owners of personal and commercial vehicles. A comparable drop in crime rates has also been observed across other major cities like Kolkata, Chennai, and Mumbai.(9)

- According to the real-time water analysis of the Central Pollution Control Board of India (CPCB) and reports of Dr Mishra, an IIT professor in Banaras Hindu University, a $40-50 \%$ enhancement has been detected in the water quality of the Ganga River (CPCB 2020).(10)

\section{Conclusion}

All these positive aspects come at a greater price of death, sickness, and a depressed global economy. Even though heart-breaking frightening is this crisis, its positive outcomes can be gifts, we should not overlook it and will be up to us to change ourselves and our environment to continue with the positive environmental impact, peace, connectedness, innovation, corporate responsibility, reimagined education, and gratitude. This crisis will end, and the human beings should take forward the positive lessons learnt, further, forward to make the world sustainable.

\section{References}

1. Gupta S, Jawanda MK. The impacts of COVID-19 on children. Acta Paediatr [Internet]. 2020;109(11):2181-3. Available from: https://doi.org/10.1111/apa.15484. Accessed on 25/09/2021

2. Nelson B. The positive effects of covid-19. BMJ2020;369:m1785.

3. Roberts $H$ M, Shafran R. Reasons to be cheerful: the other global crisis BMJ 2020; 370: $\mathrm{m} 2627$

4. Arif M, Kumar R, Parveen shagufta. Reduction in Water Pollution in Yamuna River Due to Lockdown Under COVID-19 Pandemic. Pharma Innov J. 2020;9(12):84-9.

5. Since January 2020 Elsevier has created a COVID-19 resource centre with free information in English and Mandarin on the novel coronavirus COVID-19. The COVID-19 resource centre is hosted on Elsevier Connect, the company's public news and information . 2020;01:19-21.

6. COVID-19: can we stop it being this generation's Great Depression? I InSight+. Available from https://insightplus.mja.com.au/2020/14/covid-19-can-we-stop-itbeing-this-generations-great-depression/. Accessed on 25/09/2021

7. The Hindu Explains | Is COVID-19 intensifying in rural India? - The Hindu. Available from https://www.thehindu.com/news/national/the-hindu-explains-iscovid-19-intensifying-in-rural-india/article32476163.ece. Accessed on $25 / 09 / 2021$

8. Jiang $X-Q$, Mei $X-D$, Feng $D$. Air pollution and chronic airway diseases: what should people know and do? J Thorac Dis. 2016;8(1):E31-40.

9. 6 Ways The Covid 19 Is Making A Positive Impact-Vikram Kumar BW Businessworld [Internet]. [cited 2021 May 25]. Available from: http://www.businessworld.in/article/6-Ways-The-Covid-19-IsMaking-A-Positive-Impact/12-05-2020-191781/ Accessed on $25 / 09 / 2021$

10. Khan I, Shah D, Shah SS. COVID-19 pandemic and its positive impacts on environment: an updated review. Int J Environ Sci Technol [Internet]. 2021;18(2):521-30. Available from: https://doi.org/10.1007/s13762-020-03021-3 . Accessed on 25/09/2021

\section{Figures}

FIGURE 1 POSITIVE AND NEGATIVE EFFECTS OF COVID-19

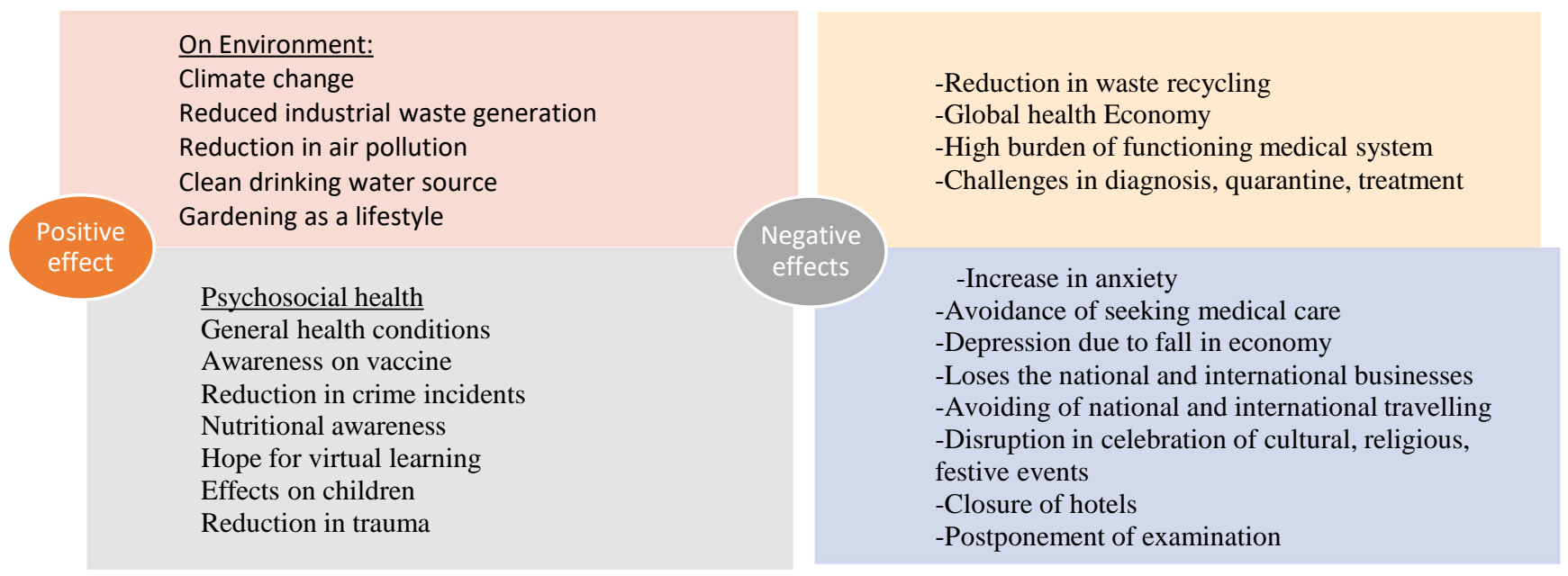

